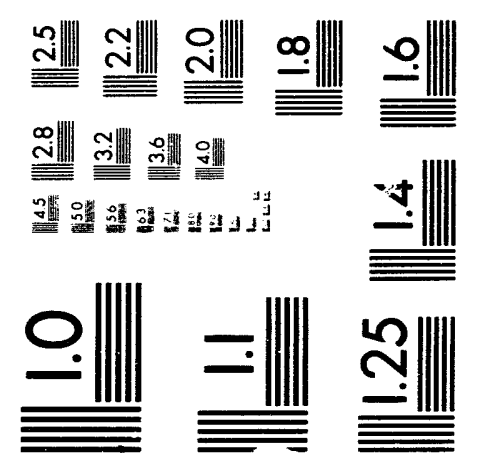



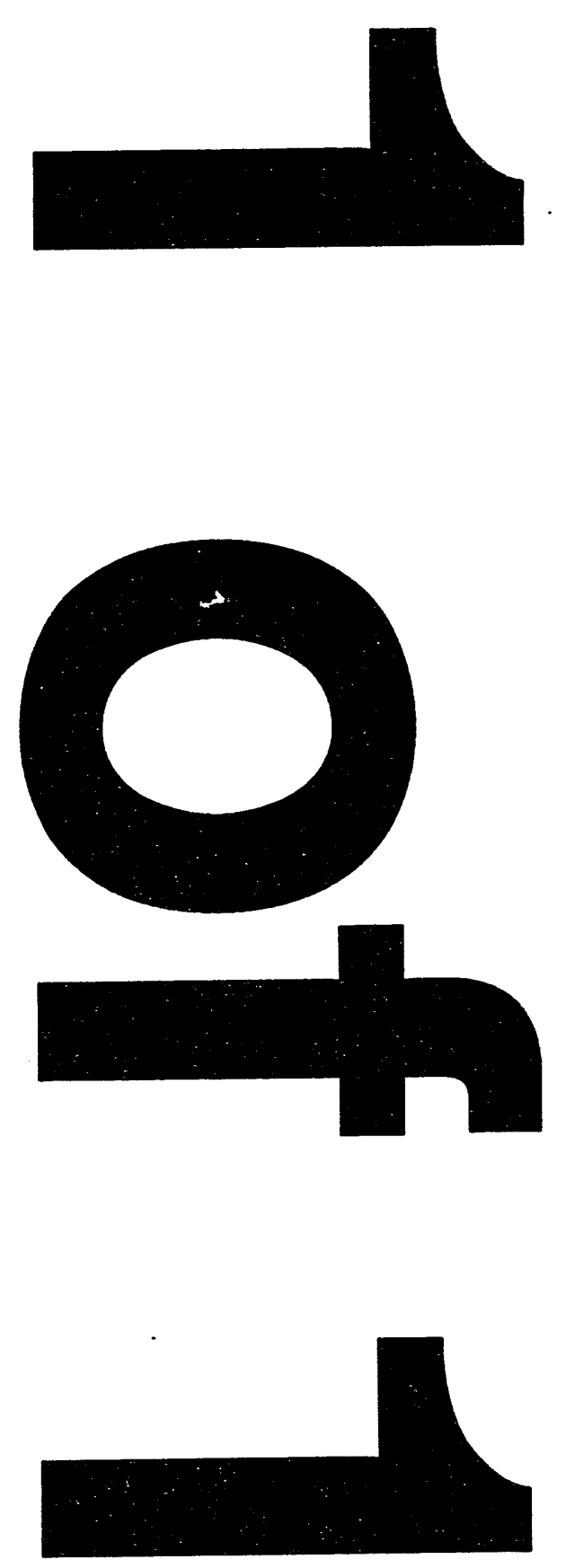
This report was prepared as an account of work sponsored by an agency of the United States Government. Neither the United States Government nor any agency thereof, nor any of their employees, makes any warranty, express or implied, or assumes any legal liability or responsibility for the accuracy, completeness, or usefulness of any information, apparatus, product, or process disclosed, or represents that its use would not infringe privately owned rights. Reference herein to any specific commercial product, process, or service by trade name, trademark, manufacturer, or otherwise does not necessarily constitute or imply its endorsement, recommendation, or favoring by the United States Government or any agency thereof. The views and opinions of authors expressed herein do not necessarily state or reflect those of the United States Government or any agency thereof.

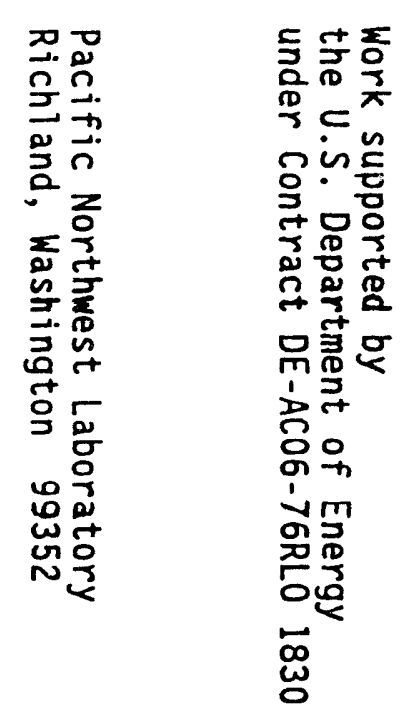

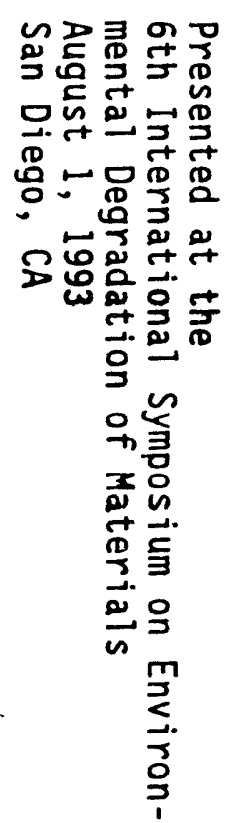

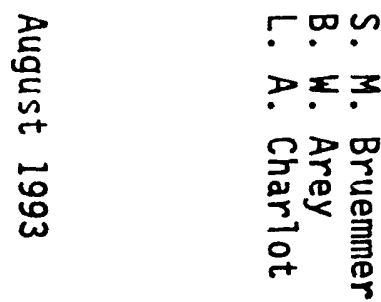
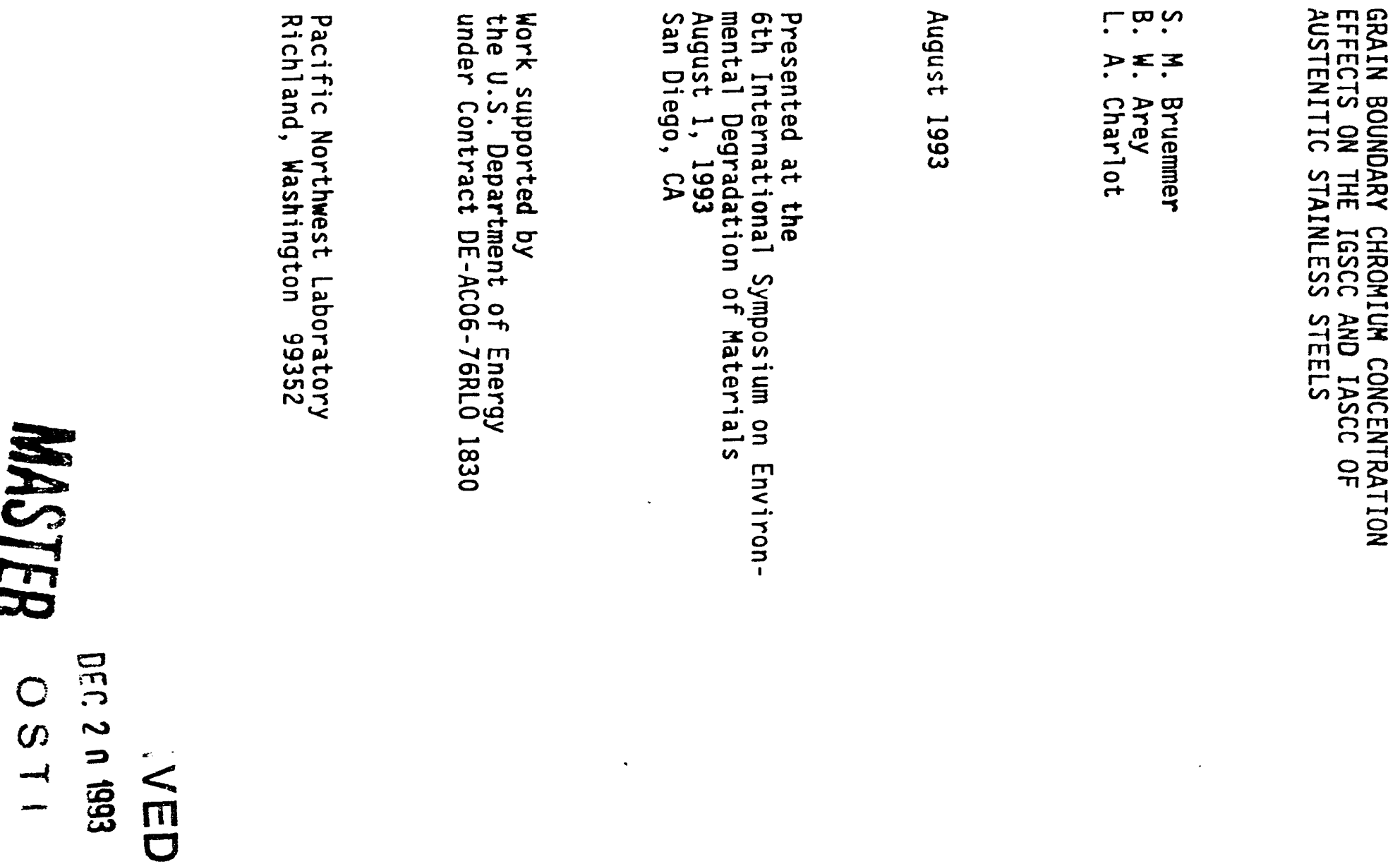


\title{
Grain Boundary Chromium Concentration Effects on the IGSCC and IASCC of Austenitic Stainless Steels
}

\author{
S. M. Bruemmer, B. W. Arey and L. A. Charlot \\ Pacific Northwest Laboratory \\ Richland, WA
}

\begin{abstract}
Comparisons are made between grain boundary composition and intergranular stress corrosion cracking (IGSCC) of 304 and 309 austenitic stainless steels in hightemperature water environments. Chromium depletion had the dominant effect on cracking resistance with the extent of IG cracking controlled by the interfacial chromium concentration. The minimum chromium concentration required to promote cracking was a function of the applied strain rate during slow-strain-rate tensile tests in $288^{\circ} \mathrm{C}$ air-saturated water. Depletion from bulk levels of $18 \mathrm{wt} \%$ to $\sim 13.5 \mathrm{wt} \% \mathrm{Cr}$ at grain boundaries prompted $100 \%$ IG cracking at a strain rate of $1 \times 10^{-6} \mathrm{~s}^{-1}$, while embrittlement was observed with only a slight depletion to $\sim 17 \mathrm{wt} \%$ at $2 \times 10^{-7} \mathrm{~s}^{-1}$. Insights into critical interfacial compositions promoting IGSCC are discussed in reference to cracking of irradiated stainless steel core components.
\end{abstract}

\section{Introduction}

Intergranular stress corrosion cracking (IGSCC) of sensitized austentic stainless steels has been extensively studied and is qualitatively well understood. Material susceptibility to cracking (and corrosion) results from the formation of a chromiumdepleted region along grain boundaries adjacent to growing chromium carbides. Much of the quantitative research in this area was prompted in response to stainless steel pipe cracking in boiling water reactor systems resulting from welding-induced sensitization. 1 The combination of weld residual stresses and the high-temperature $\left(288^{\circ} \mathrm{C}\right)$ water environment is sufficiently aggressive to promote IGSCC.

A more recent concern in nuclear reactor systems is the failure of stainless steel core 
components due to irradiation-assisted (IA) SCC. Cracking is again IG in these components and grain boundary chromium depletion (and other changes in interfacial chemistry) is produced by irradiation. This radiation-induced segregation (RIS) is believed to be important in the cracking mechanism.2,3 However, little definitive information is available to quantify microstructural and microchemical aspects that control this phenomenon. Understanding the independent effects of chromium depletion on IGSCC is critical for assessing the importance of RIS on the mechanism of cracking.

The purpose of this research is to examine and quantify the influence of grain boundary chromium depletion and carbide precipitation on the IGSCC of 304 and 309SS in high-temperature water. Complex heat treatments are used to produce controlled grain boundary microstructures and microchemistries. Microstructures and microchemistries are documented and compared to IGSCC susceptibility during slowstrain-rate (SSR) tensile tests in $288^{\circ} \mathrm{C}$ aerated water. Current work follows previously published research 4 on 304SS at higher strain rates and enables the influence of strain rate and grain boundary carbides on IGSCC to be assessed. Relationships between interfacial chromium concentrations and cracking are developed and used to determine if radiation-induced chromium depletion can explain the observed IASCC of stainless steel core components.

\section{Materials}

\section{Experimental Procedure}

High-carbon 304 and $3095 S$ plate materials were selected for study. The main differences in bulk composition between these heats are higher chromium and nickel levels in the 309SS. Measured compositions (in wt\%) are $0.06 \mathrm{C}, 18.48 \mathrm{Cr}, 8.75 \mathrm{Ni}$, $0.2 \mathrm{Mo}, 1.7 \mathrm{Mn}, 0.39 \mathrm{Si}, 0.065 \mathrm{~N}, 0.013 \mathrm{P}$ and $0.012 \mathrm{~S}$ for the $304 \mathrm{SS}$ and $0.06 \mathrm{C}, 22.0$ $\mathrm{Cr}, 12.0 \mathrm{Ni}, 0.2 \mathrm{Mo}, 1.7 \mathrm{Mn}, 0.7 \mathrm{Si}, 0.04 \mathrm{~N}, 0.02 \mathrm{P}$ and $0.02 \mathrm{~S}$ for the $309 \mathrm{SS}$. Specimens were solution annealed at $1100^{\circ} \mathrm{C}$ for 1 hour and water quenched. The resultant microstructures contained few second-phase particles and had grain sizes of $\sim 120$ and $\sim 105 \mu \mathrm{m}$ for 304 and 309SS, respectively. Samples were then heat treated 
to produce controlled carbide precipitation and chromium depletion profiles.

A heat treatment of $650^{\circ} \mathrm{C}$ for $25 \mathrm{~h}$ was employed to produce a severely sensitized microstructure (i.e., near-continuous distribution of carbides at boundaries with significant chromium depletion). Subsequent treatments at higher temperatures (800 to $1000^{\circ} \mathrm{C}$ ) were used to modify depletion characteristics by controlled desensitization. After each individual heat treatment, the material was water quenched to maintain its high-temperature microchemistry.

\section{Microstructural and Microchemical Measurements}

Microstructural characteristics were documented by optical metallography, scanning (SEM) and transmission electron microscopy (TEM). Carbide distributions were examined metallographically after etching in a nitric-hydrochloric acid solution and by TEM. Sample preparation for TEM was done by electrochemical jetting and polishing in a 5 vol\% perchloric acid-methanol solution cooled to $-40^{\circ} \mathrm{C}$. Elemental compositions across grain boundaries were measured using a Philips EM400T TEM/STEM or a JEOL 1200 TEM/STEM, both equipped with an energy dispersive $X-$ ray spectrometer (EDS). Methods for STEM-EDS analysis of grain boundary chemistry have been described elsewhere 5 along with ql...ntification of the X-ray spectra and estimation of error. EDS analysis was obtained using a 10-nm incident electron probe. Foil thickness in analysis regions was from 50 to $100 \mathrm{~nm}$ so that through-thickness resolution was generally less than $20 \mathrm{~nm}$. This resolution was sufficient to map the broad composition profiles developed in the desensitized samples. Concentration profiles were typically taken in 2 to $10 \mathrm{~nm}$ steps across boundaries and between carbides that were more than $0.3 \mu \mathrm{m}$ apart.

\section{EPR and SCC Tests}

Electrochemical potentiokinetic reactivation (EPR) and SSR-SCC tests were conducted on the stainless steel specimens. The procedure for EPR testing has been described previously. 6 In general, the single-loop EPR method follows the approach 
of Clarke, et al. 7 that was developed for 304SS. An identical testing and analysis procedure was employed for both the 304 and 309SSs.

Stress corrosion susceptibility was evaluated by SSR $\left(1 \times 10^{-6} \mathrm{~S}^{-1}\right.$ or $\left.2 \times 10^{-7} \mathrm{~s}^{-1}\right)$ tensile tests in $288^{\circ} \mathrm{C}$, laboratory air-saturated $(\sim 8 \mathrm{ppm} \mathrm{O}$ ) water held at $10.3 \mathrm{MPa}(1500 \mathrm{psi})$. Dog-bone tensile specimens, $113-\mathrm{mm}$ long and 5-mm thick, were machined with a 25$\mathrm{mm}$ gage length and 4-mm width. Gage sections were wet-sanded with 600-grit SiC paper before insertion in a once-through autoclave system (flow rate of $\sim 0.1$ liter $/ \mathrm{h}$ ). Water chemistry, conductivity and $\mathrm{pH}$ were determined before and after individual tests. Typical effluent analysis showed a pH of 6.2 and a conductivity of $<1 \mu \mathrm{S} / \mathrm{cm}$ with concentrations of $<20 \mathrm{ppb}$ for chlorides and sulfates by ion chromatography, and is comparable to inlet water chemistry. Specimens were exposed to the hightemperature water for $\sim 0.5 \mathrm{~h}$ before straining was started. Electrochemical potential was not controlled nor measured during SCC testing. Fracture surfaces were examined using SEM and the \%IGSCC was quantified as described previously. 4

\section{Results \& Discussion}

\section{Grain Boundary Microstructure and Microchemistry}

An inherent problem in examining sensitization development in stainless steels is the variability in precipitation kinetics at different grain boundaries. To minimize boundaryto-boundary inconsistency, specimens were given an initial heat treatment $\left(650^{\circ} \mathrm{C} / 25 \mathrm{~h}\right)$ to establish a very high density of chromium carbides at nearly all grain interfaces. This treatment resulted in a near-continuous carbide distribution along high-angle grain boundaries and an EPR value $>90 \mathrm{C} / \mathrm{cm}^{2}$. The carbides effectively pin grain boundaries during subsequent high-temperature heat treatment.

Examples of heat treatment temperature effects on carbide distributions in 304 and $309 \mathrm{SS}$ are shown in Figures 1. A $25-\mathrm{h}$ anneal at $900^{\circ} \mathrm{C}$ increases the size of IG carbides in both materials, but they remain in a near-continuous distribution as 
indicated by the attack in the nitric-hydrochloric solution. Average carbide spacing changed significantly (from $<0.5 \mu \mathrm{m}$ to $>2 \mu \mathrm{m}$ apart) in the 304SS after several hours at $950^{\circ} \mathrm{C}$ as indicated by comparing Figures $1(a)$ and $1(b)$. After $8 \mathrm{~h}$ at this temperature, certain boundaries exhibited only isolated carbides. However, very little change in spacing is observed in the higher chromium, 309SS at this temperature. Carbides remained nearly continuous ( $<0.5 \mu \mathrm{m}$ apart) at most boundaries after $25 \mathrm{~h}$ at $950^{\circ} \mathrm{C}$ for the $309 \mathrm{SS}$, Figure $1(\mathrm{C})$. Temperatures above $975^{\circ} \mathrm{C}$ were required to dissolve carbides in 309SS. Carbide spacings were estimated from SEM (carbideetched samples) and TEM micrographs used to document the grain boundary microstructure.

Desensitization heat treatments at high temperatures sharply modified the chromium depletion profile along grain boundaries. Initial interfacial chromium levels were below $11 \mathrm{wt} \%$ after the $650^{\circ} \mathrm{C} / 25 \mathrm{~h}$ treatment with a total depletion width of $\sim 50 \mathrm{~nm}$ for both SSs. The $900^{\circ} \mathrm{C} / 25 \mathrm{~h}$ anneal increases the boundary minimum to $\sim 15.5 \mathrm{wt} \%$ in 304SS (matrix concentration of $\sim 17.5 \mathrm{wt} \%$ ). A wide, but shallow, chromium-depleted zone was measured at most boundaries. Heat treatments at $950^{\circ} \mathrm{C}$ eliminate this slight depletion, but also dissolve many boundary carbides as noted above. Examples of typical chromium depletion profiles are presented in Figure 2 for the 304SS. By comparison, the 309SS required higher temperatures to achieve similar levels of desensitization. Grain boundary chromium concentrations remained near 13 wt\% after the $900^{\circ} \mathrm{C} / 25 \mathrm{~h}$ desensitization treatment and increased to $\sim 18 \mathrm{wt} \%$ after $25 \mathrm{~h}$ at $950^{\circ} \mathrm{C}$.

Chromium depletion, carbide spacing and EPR measurements are correlated in Figure 3 for each material condition. An important difference between the 304 and $309 S$ S behavior is that higher boundary chromium levels could be produced in the 309 specimens, while maintaining continuous to semi-continuous carbide distributions. Estimated carbide spacing sharply increases as interfacial chromium contents approached $17 \mathrm{wt} \%$ in the 304SS, while a similar increase in spacing does 
not occur in 309SS until chromium contents exceed $\sim 19 w t \%$. EPR-measured degree of sensitization (DOS) decreases with increasing grain boundary chromium concentration up to the critical concentration of $\sim 13.5 \mathrm{wt} \%$ for both steels. Therefore, most of the "desensitized" samples have no measureable EPR-DOS, but retain closely spaced carbides and significant chromium depletion. A detailed comparison between chromium depletion and EPR measurement was described in an earlier publication. 6

\section{Chromium Depletion Effects on IGSCC}

Prior work 4 on $304 S S$ documented a sharp change in fracture behavior during SSR tests at a strain rate of $1 \times 10^{-6 / \mathrm{s}}$ in $8 \mathrm{ppm} \mathrm{O}_{2}, 288^{\circ} \mathrm{C}$ water as the interfacial chromium content decreased from $\sim 16$ to $12 \mathrm{wt} \%$. Intergranular fracture increased to $>90 \%$, and the strain-to-failure dropped from 50 to $15 \%$ as shown by the solid points in Figures $4(a)$ and (b), respectively. The five times slower strain raie employed for the current tests (open points) promoted severe IG cracking (Figure 5a) at much higher interfacia! chromium concentrations. More than 90\% IG fracture and strain-to-failure values of only 10 to $15 \%$ were observed for 304 SS specimens with chromium levels less than $\sim 17 \mathrm{wt} \%$. The fracture mode changed to predominately transgranular (Figure $5 \mathrm{~b}$ ) and ductility increased as grain boundary chromium concentrations reached $17.5 \mathrm{wt} \%$.

A major difficulty in isolating the influence of chromium depletion is that grain boundary carbide distributions change during desensitization heat treatments that produce IGSCC resistance in 304SS. The highest chromium contents (17.5 and 18.2 wt\%) produced in $304 \mathrm{SS}$ required $950^{\circ} \mathrm{C}$ anneals ( 8 and $25 \mathrm{~h}$ ) which promoted extensive carbide dissolution and isolated boundary carbides. Thus, an independent effect of boundary carbides on IGSCC could not be eliminated based on the $304 S S$ tests alone. To examine the effect of higher chromium contents on IGSCC, desensitized 309SS was evaluated where near-continuous carbides could be maintained at chromium levels above $17 \mathrm{wt} \%$. Initial test results documented by the crosshatched points in Figure 4 are consistent with the 304SS data. Ductile failure is observed at a grain boundary concentration of $18 \mathrm{wt} \%$ (Figure $5 \mathrm{c}$ ) even with continuous carbides present. The 3095 results indicate that continuous IG carbides 
are not a sufficient condition for IGSCC (without chromium depletion) as speculated previously. 4 A critical depletion in interfacial chromium content to about $17 \mathrm{wt} \%$ is necessary to promote IGSCC under these test conditions. This represents a very small depletion for 304 SS ( 1 wt \%). The observation of severe IGSCC in the desensitized SSs with very wide $(\sim 0.5 \mu \mathrm{m})$ chromium depletion profiles suggests that localized grain boundary chromium depletion is not required to induce a high IG crack growth rate.

\section{Radlation-Induced Chromium Depletion}

In stainless steels, major alloying elements such as iron, nickel and chromium, are directly influenced by the flow of radiation-induced vacancies to grain boundaries. The slowest diffusing element (nickel) becomes enriched at sinks, while faster diffusers (chromium and iron) are depleted. Undersized minor elements and impurities such as silicon and phosphorus bind with interstitials and migrate preferentially to sinks. Grain boundary composition has been reported in a number of neutron-irradiated SSs.8-18 At present, the most complete data has been generated using FEG-STEM with an incident electron probe diameter from 2 to $3 \mathrm{~nm}$ and throljghfoil thicknesses less than $75 \mathrm{~nm}$. This results in an analysis resolution of about 3 to 5 $\mathrm{nm}$ that enables measurement of narrow, radiation-induced enrichment and depletion profiles.

Radiation-induced chromium depletion has been the focus of many IASCC studies because of its well documented effects in promoting IGSCC in sensitized stainless steels. Grain boundary chromium concentrations measured in neutron-irradiated 304 , 316 and 348 SSs have been compiled and analyzed.20 Minimum chromiurn concentrations are plotted as a function of fluence in Figure 6. The plotted data has been adjusted to account for the effect of chromium-rich surface films on the measured concentrations. Grain boundary concentrations have been reduced by the difference (typically $\sim 1 \%$ ) between the measured matrix chromium and the bulk content. No attempt has been made to deconvolute the measured profiles to more accurately 
determine the true interfacial concentration for these narrow profiles. However, as noted above, the minimum chromium level measured has been used. Numerous reasons exist why FEG-STEM may underestimate RIS in neutron-irradiated stainless steels (particularly at low fluences), but there are few reasons fc" the opposite to be true. Therefore, the values plotted in Figure 6 are believed to better represent compositions at the boundaries which control SCC than an average of two different boundaries typically examined. It is likely that the actual minimum concentrations are below those reported due to beam dilution effects and the limited number ( 2 per sample) of boundaries analyzed.

The most detailed characterization of neutron fluence effects on grain boundary RIS has been reported by Jacobs ${ }^{8}$ on 304 SSs. A consistent decrease in interfacial chromium was detected with increasing fluence up to $\sim 2 \times 1021 \mathrm{n} / \mathrm{cm}^{2}$, i.e. about 3 dpa. Samples irradiated to slightly higher fluences did not show a continued decrease in the grain boundary chromium level. This change in the rate of depletion is in agreement with the few high-fluence data points in Figure 6, with charged particle irradiations 21 and with model predictions. 22 The heat-to-heat variability is indicated by the more recent data of Jacobs, et al.18 on thirteen different heats of 316SS irradiated to a fast neutron fluence of $2.3 \times 1021 \mathrm{n} / \mathrm{cm}^{2}$. Grain boundary chromium depletion is observed in all heats, but the amount of measured depletion ranged from 2 to $9 \%$. Again only two boundaries were analyzed per material with considerable variability between the two reported measurements. Considering the wide range of materials and starting conditions, most data shows a consistent exponential decrease in chromium content with increasing fluence.

\section{Radiation-Induced Chromium Depletion \& IGSCC}

Data8,13,16-19 where radiation-induced chromium depletion and IGSCC have been measured are summarized in Figure 7. The SSR tests are limited, but indicate that some level of depletion exists in all stainless steels which fail by IGSCC. As the grain boundary chromium concentration drops below $\sim 16 \mathrm{wt} \%, 304$ SS becomes susceptible to cracking under the specific conditions of the test. The data points for 
316 SS suggest a lower minimum, corresponding to an interfacial chromium depletion of $\sim 2$ wt\% below the matrix, consistent with the 304SS results. Included in Figure 7 are in-core eddy current measurements 8 and swelling mandrell test results 18 which indicate the extent of IGSCC based on the percentage of cracked components. Many differences exist between the in-situ straining tests and post-irradiation SSR tests, but data from each source only show cracking in samples with some degree of chromium depletion. Significant cracking is identified when chromium levels drop below $16 \mathrm{wt} \%$.

The relationship established between thermally induced chromium depletion and IGSCC from Figure 4(a) has been plotted with the irradiated materials data in Figure 7. All irradiated specimens that show IG cracking have sufficient grain boundary chromium depletion for IGSCC susceptibility in the SSR tests. Thus, chromium depletion can explain the observations of IGSCC without considering other radiation effects on microstructure and microchemistry. However, questions still remain as to why a few chromium-depleted SSs show more resistance to IGSCC. In particular, Jacobs, et al.18 identified very significant radiation-induced chromium depletion (down to $\sim 13.5 \mathrm{wt} \%$ ) in several 316 SS heats which were resistant to IGSCC. Protonirradiated high-purity 304-type SSs have also shown an improved cracking resistance in SSR tests for certain alloys exhibiting severe chromium depletion.23 No correlation has been found between chromium content and IASCC. These results strongly suggest that other microstructural (e.g., radiation hardening) and/or microchemical (grain boundary or adjacent matrix) aspects influence cracking susceptibility. Since radiation-induced chromium depletion widths are very narrow, differences in deformation or passivation characteristics among SS heats may strongly impact crack initiation and growth processes.

\section{Conclusions}

Chromium depletion effects on the IGSCC of austenitic stainless steels in hightemperature water are found to depend on the test strain rate. The critical grain boundary chromium concentration required to promote cracking increased from 
$\sim 14 \mathrm{wt} \%$ at a strain rate of $1 \times 10^{-6} \mathrm{~s}^{-1}$, to $\sim 17.5 \mathrm{wt} \%$ at $2 \times 10^{-7} \mathrm{~s}^{-1}$. A high density of IG carbides (without chromium depletion) is not a sufficient condition to promote IGSCC. Analysis of radiation-induced chromium depletion measurements and SCC behavior demonstrates that IASCC-susceptible material have grain boundary chromium contents below the critical concentration for cracking observed in thermally sensitized specimens. Although chromium depletion plays an important role in IASCC, it is clear that cracking susceptibility is not a simple function of this microchemical change.

\section{Acknowledgements}

This research was supported by the Materials Sciences Branch, Office of Basic Energy Sciences, U.S. Department of Energy, under Contract DE-AC06-76RLO 1830.

\section{References}

1. BWROG Intergranular Stress Corrosion Cracking Research Program: Executive Summaries, Phase I - EPRI NP-4273-SR (1985) and Phase II - EPRI NP-6927, (1990), Electric Power Research Institute, Palo Alto, CA.

2. P. L. Andresen, F. P. Ford, S. M. Murphy, and J. M. Perks, "State of Knowledge of Radiation Effects on Environmental Cracking in Light Water Reactor Core Materials," Proc. 4th Int. Symp. on Environmental Degradation of Materials in Nuclear Power Systems - Water Reactors, D. Cubicciotti and G. J. Theus, Eds., Jekyll Island, GA, August 1989, NACE, Houston, 1990, p. 1-83.

3. P. L. Andresen, "Irradiation-Assisted Stress Corrosion Cracking," Stress Corrosion Cracking, ed. R. H. Jones, ASM International, Metals Park, OH, 1992.

4. S. M. Bruemmer, B. W. Arey and L. A. Charlot, Corrosion, 48 (1), 1992, p. 42.

5. S. M. Bruemmer, L. A. Charlot, Scr. Metall., 20, 1019, 1986.

6. S. M. Bruemmer, Corrosion, 42(1), 27, 1986.

7. W. L. Clarke, NUREG-0251-1, Aug. 1976 and NUREG/CR-1095, Feb. 1981, U.S.Nuclear Regulatory Commission, Washington, DC.

8. A. J. Jacobs, "Relationship of Grain Boundary Composition in Irradiated Type 304 SS to Neutron Fluence and IASCC," 16th ASTM Symp. Radiation Effects on Materials, Denver, 1992. 
9. K. Asano, K. Fukuya, K. Nakata and M. Kodama, "Changes in Grain Boundary Composition Induced by Neutron Irradiation on Austenitic Stainless Steels," ibid 6, p. 838.

10. E. A. Kenik, J. Nucl. Mater., 187, 1992, p. 239.

11. A. J. Jacobs, R. E. Clausing, M. K, Miller and C.M. Shepherd, "Influence of Grain Boundary Composition on the IASCC Susceptibility of Type 348 Stainless Steel," ibid 1, p. 14-21.

12. S. Nakahigashi, M. Kodama, K. Fukuya, S. Nishimura, S. Yamamoto, K. Saito and T. Saito, J. Nucl. Mater., 179-181, 1991, p. 1061.

13. C. M. Shepherd and T. M. Williams, "Simulation of Microstructural Aspects of IASCC in Water Reactor Core Components," ibid 1, p. 14-11.

14. A. J. Jacobs, R. E. Clausing, L. Heatherly and R. M. Kruger, "Irradiation-Assisted Stress Corrosion Cracking and Grain Boundary Segregation in Heat Treated Type 304 SS," 14th Int. Symp. Radiation Effects on Materials, Andover, MA, 1988.

15. Proc. Symp. Radiation-Induced Sensitization of Stainless Steels, D. I. R. Norris, Ed., Berkeley Nuclear Laboratories, September 1986, CEGB, INIS-GB-90.

16. A. J. Jacobs, C. M. Shepherd, G. E. C. Bell and G. P. Wozadlo, "High-Temperature Solution Annealing as an IASCC Mitigation Technique," ibid 6, p. 917.

17. H. M. Chung, W. E. Ruther, J. E. Sanecki and T. F. Kassner, "Irradiation-Induced Sensitization and Stress Corrosion Cracking of Type 304 Stainless Steel CoreInternal Components," ibid 6. Also Semi-Annual Reports, Environmentally Assisted Cracking in Light Water Reactors, NUREG/CR-4667, Vol. 13 and 14, Nuclear Regulatory Commission, 1992.

18. A. J. Jacobs, G. P. Wazadlo, K. Nakata, S. Kasahara, T. Okada, S. Kawano and S. Suzuki, "The Correlation of Grain Boundary Composition in Irradiated Stainless Steel with IASCC Resistance," Proc. 6th Int. Symp. on Environmental Degradation of Materials in Nuclear Power Systems - Water Reactors, E. P. Simonen and R. Gold, Eds., San Diego, TMS, 1993, in press.

19. M. Kodama, S.Nishimura, J. Morisawa, S. Suzuki, S. Shima and M. Yamamoto, "Effects of Fluence and Dissolved Oxygen on IASCC in Austenitic Stainless Steel," Proc. 5th'Int. Symp. on Environmental Degradation of Materials in Nuclear Power Systems - Water Reactors, D. Cubicciotti, E. P. Simonen and R. Gold, Eds., Monterey, ANS, 1992, p. 948. 
20. S. M. Bruemmer and E. P. Simonen, "Radiation Hardening and Radiation-Induced Chromium Depletion Effects on Intergranular Stress Corrosion Cracking of Stainless Steels," Corrosion 93, National Association of Corrosion Engineers, Houston, 1993, Paper 616.

21. S. M. Bruemmer, M. D. Merz and L. A. Charlot, J. Nucl. Mater., 186, 1991, p. 13.

22. E. P. Simonen and S. M. Bruemmer, "Mechanistic Issues for Modelling RadiationInduced Segregation," Corrosion 93, National Association of Corrosion Engineers, Houston, 1993, Paper 615.

23. J. Cookson, “...", ibid 18 , in press.

\section{Figure Captions}

1. Etched surfaces showing chromium carbide distributions in desensitized steels:

(a) $304 \mathrm{SS}-1100^{\circ} \mathrm{C} / 1 \mathrm{~h}+650^{\circ} \mathrm{C} / 25 \mathrm{~h}+900^{\circ} \mathrm{C} / 25 \mathrm{~h}$, continuous grain boundary carbides; (b) $304 \mathrm{SS}$ - as for (a) $+950^{\circ} \mathrm{C} / 8 \mathrm{~h}$, individual carbides spaced along many boundaries; and (c) $309 \mathrm{SS}$ - as for (a) $+950^{\circ} \mathrm{C} / 25 \mathrm{~h}$, continuous grain boundary carbides.

2. Typical chromium depletion profiles across high-angle grain boundaries illustrating desensitization heat treatment effects on interface and near-interface chromium concentrations.

3. Interdependence of chromium depletion, EPR-DOS and carbide spacing at grain boundaries after various desensitization heat treatments. Near-continuous boundary carbides are maintained to higher chromium levels in the 309SS.

4. The influence of grain boundary chromium concentration on the \%IGSCC (a) and the strain to failure (b) during SSR testing in aerated $288^{\circ} \mathrm{C}$ water.

5. Fracture morphologies for several desensitized specimens after SSR testing: (a) $304 \mathrm{SS}-1100^{\circ} \mathrm{C} / 1 \mathrm{~h}+650^{\circ} \mathrm{C} / 25 \mathrm{~h}+900^{\circ} \mathrm{C} / 25 \mathrm{~h}$, boundary chromium $\sim 15.5 \mathrm{wt} \%$, 95\%IG; (b) $304 \mathrm{SS}$ - as for (a) $+950^{\circ} \mathrm{C} / 8 \mathrm{~h}$, boundary chromium $~ 17.5 \mathrm{wt} \%, 20 \% \mathrm{IG}$; and (c) $309 \mathrm{SS}$ - as for (a) $+950^{\circ} \mathrm{C} / 25 \mathrm{~h}$, boundary chromium $\sim 18 \mathrm{wt} \%, 0 \% \mathrm{IG}$.

6. Measured grain boundary chromium concentrations in several austenitic SSs as a function of neutron fluence.

7. IGSCC susceptibility of irradiated SSs plotted as a function of measured grain boundary chromium concentration. Results for unirradiated, desensitized 304SS samples from Figure 4(a) are shown to bound the upper end of the data. 
Fieve I

$$
\text { ล }
$$

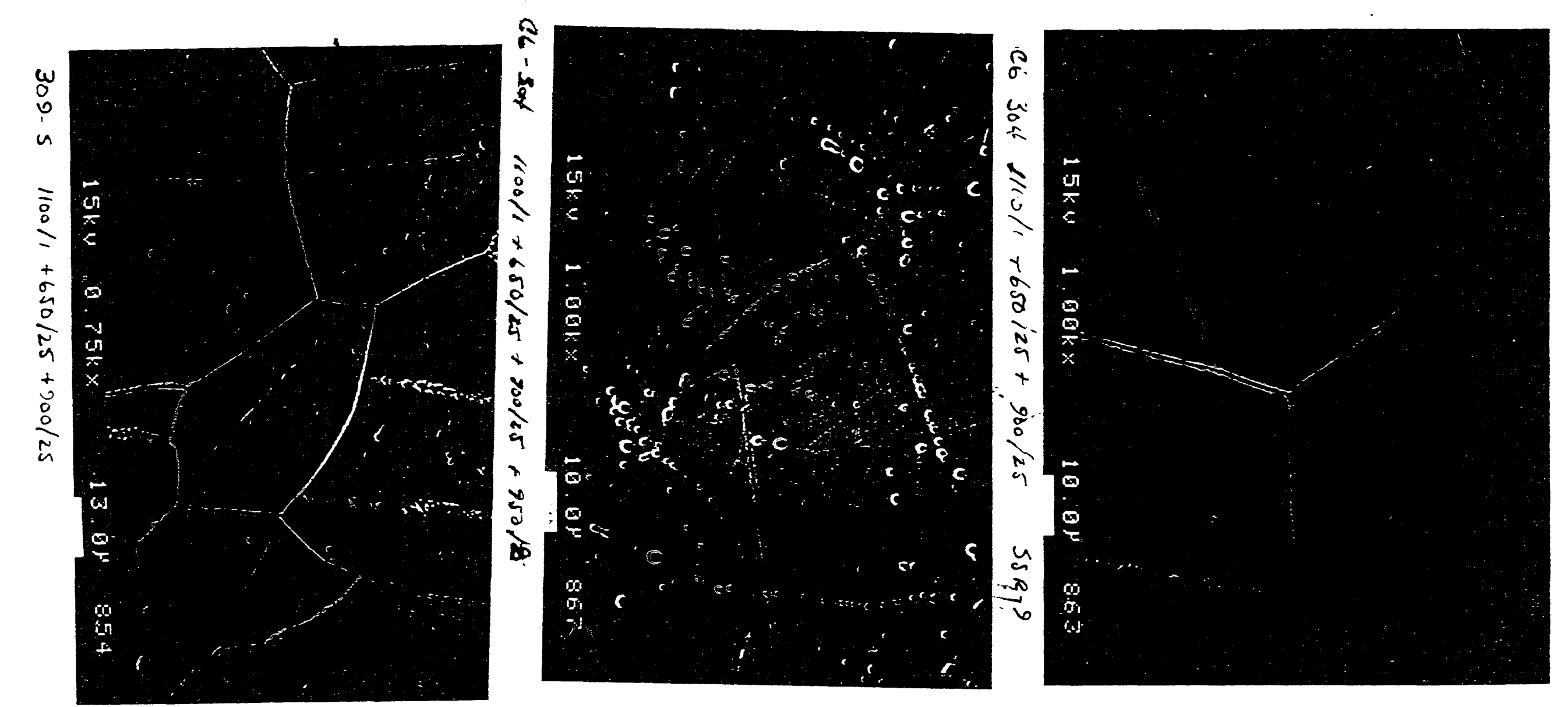




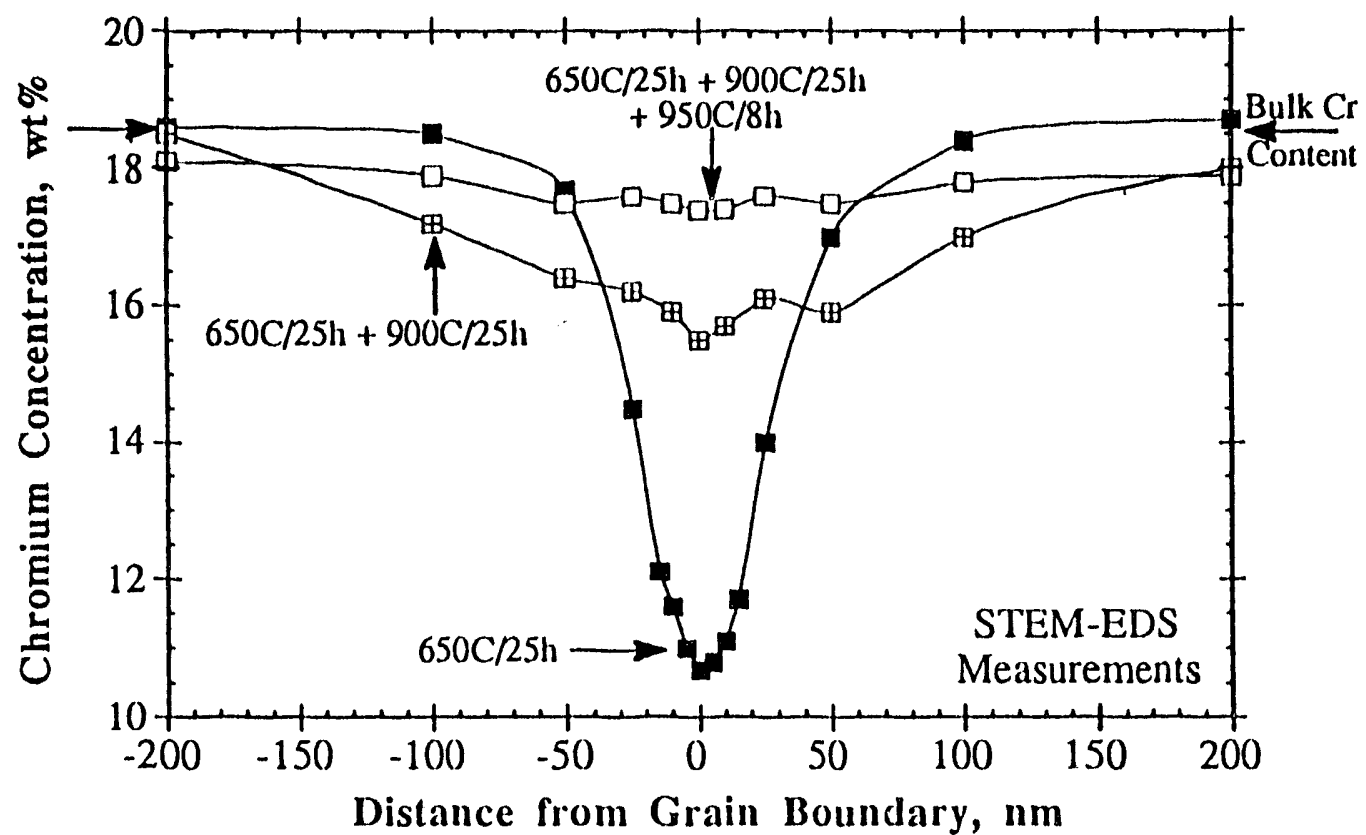

Fig 2

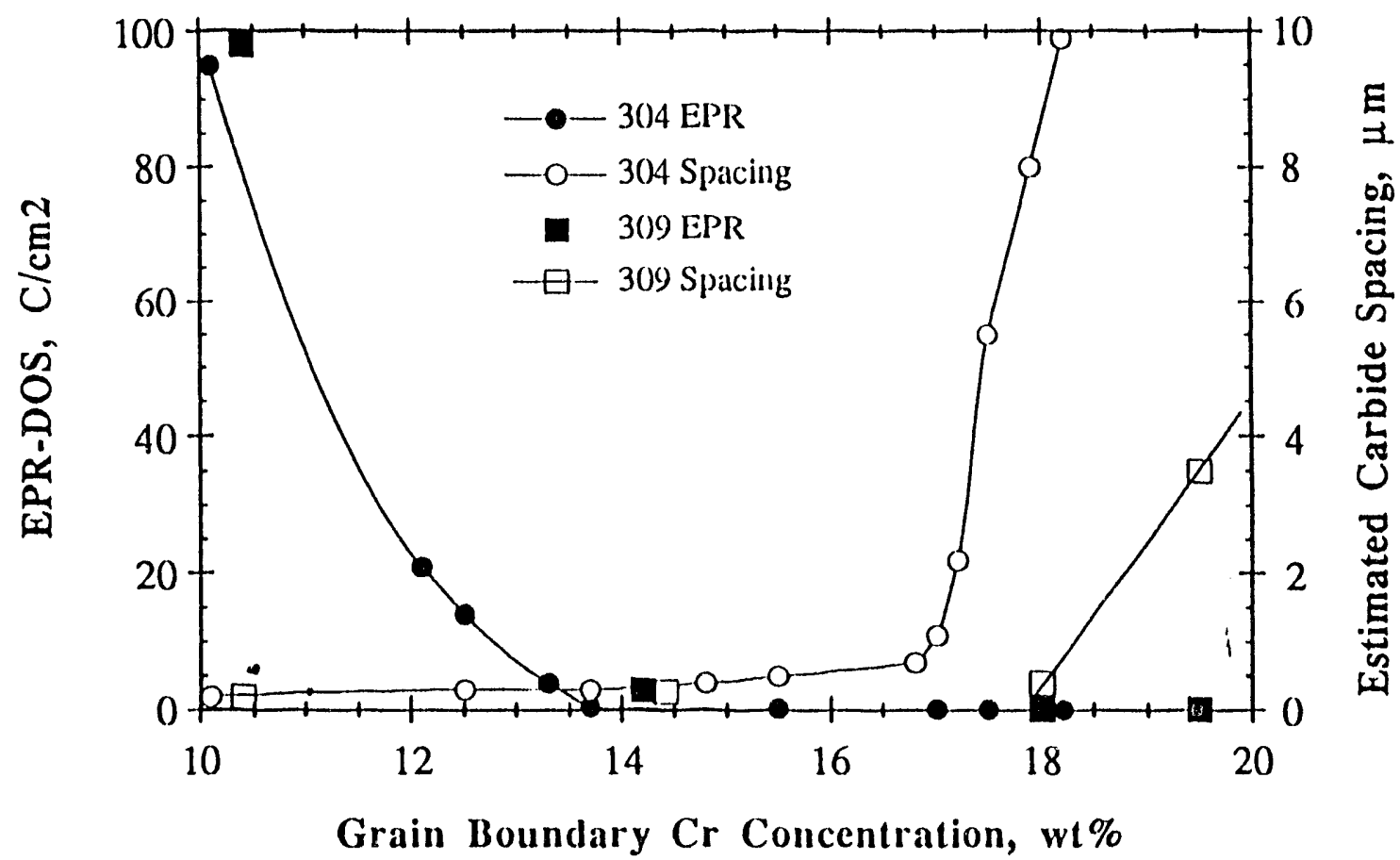

Fig 3 


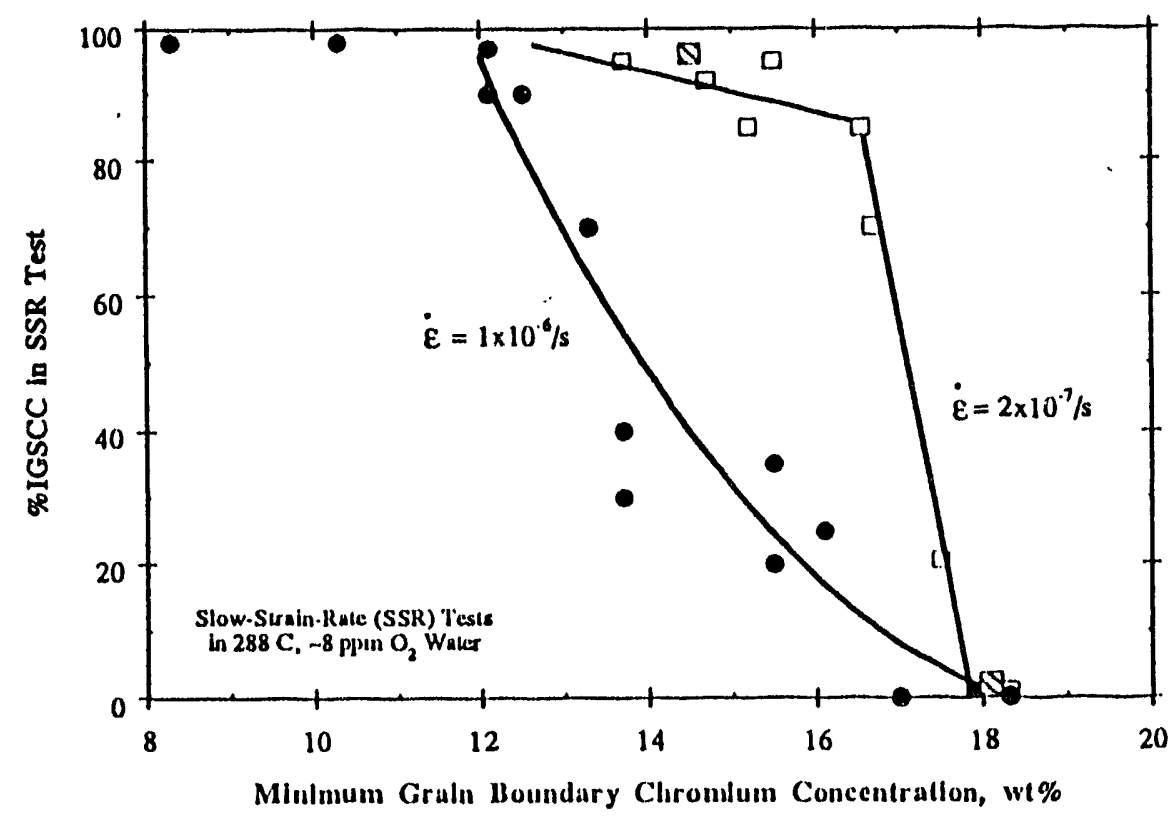

$$
\text { Fig } f(a)
$$

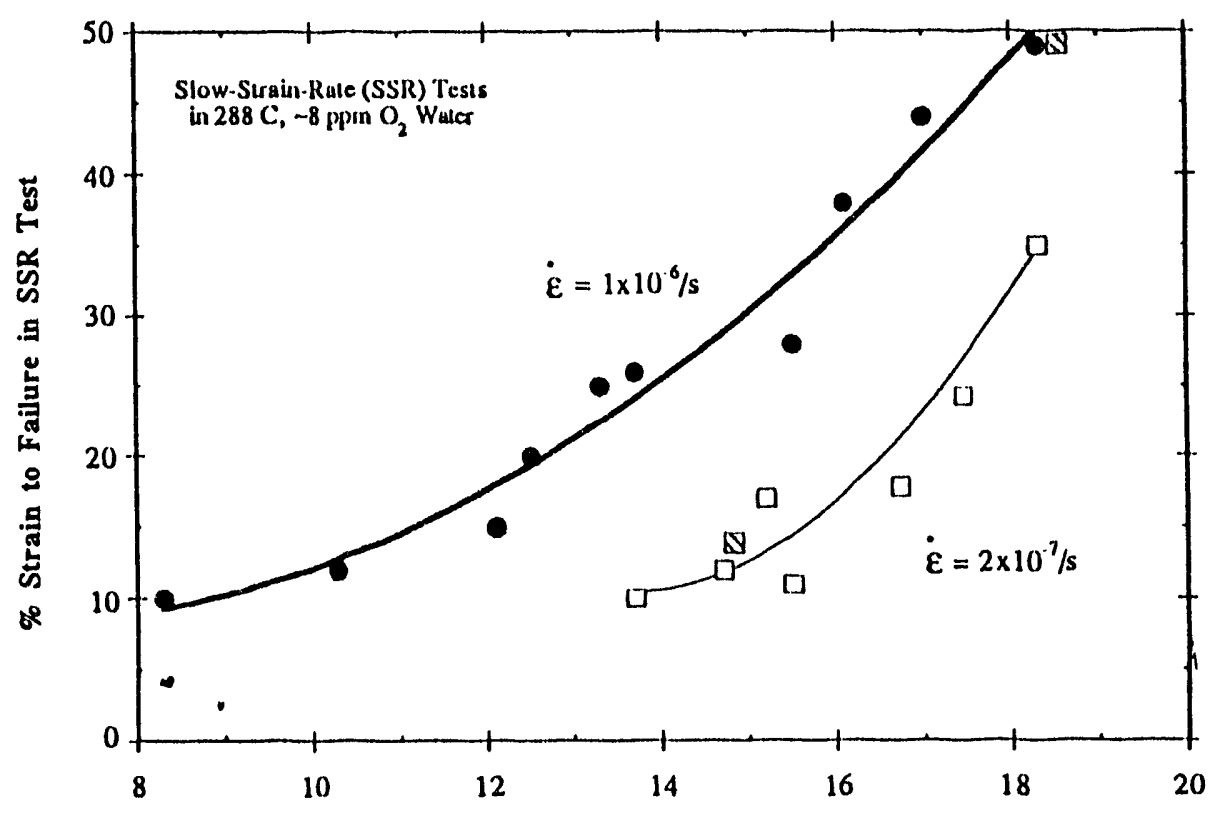

Minimum Ciralu Boundary Claromlum Concentratlon, wi\%

$$
F_{i j} f(0)
$$




$$
\text { Fig. } 5
$$

$$
\text { a }
$$$$
E
$$
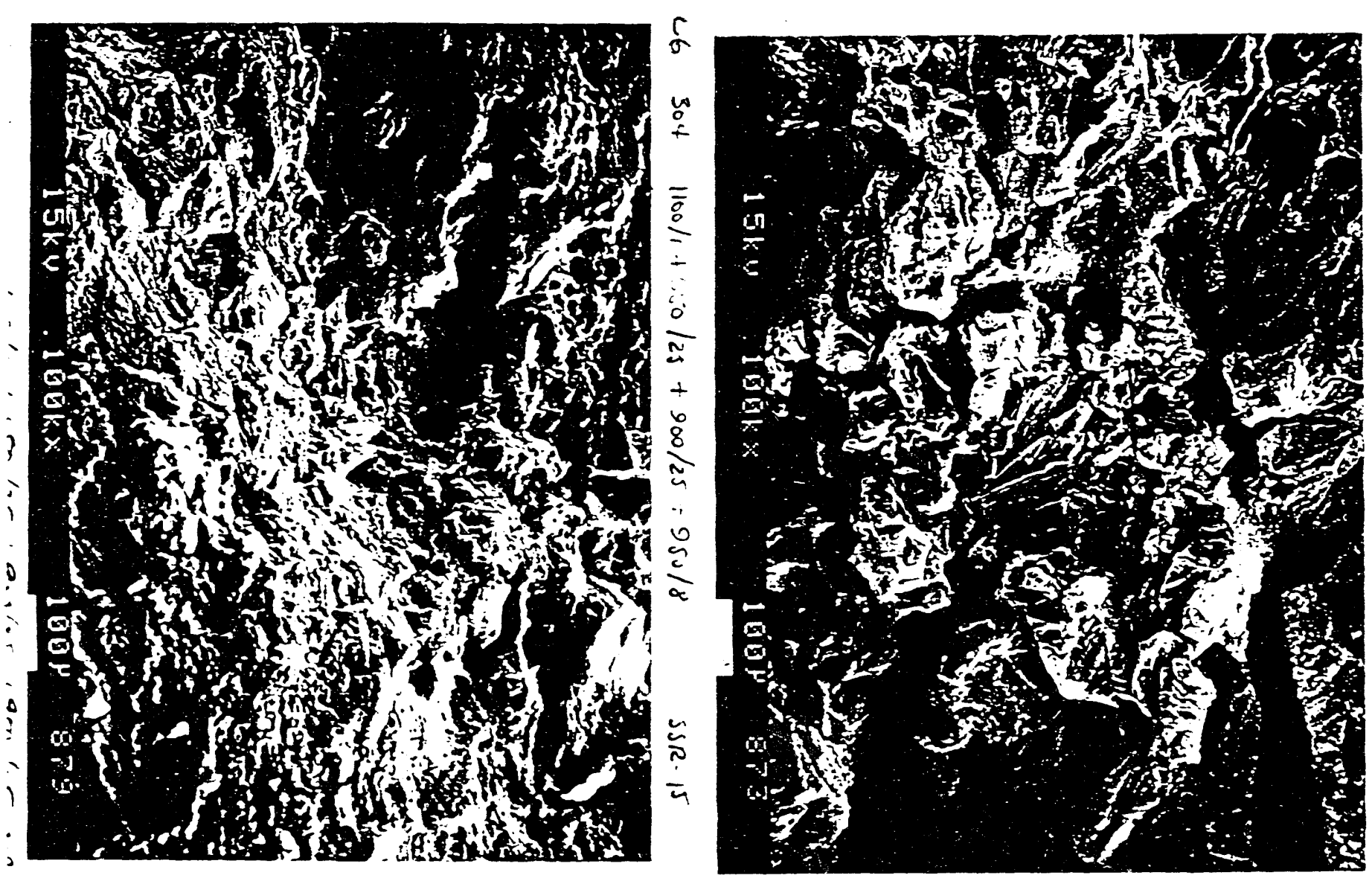

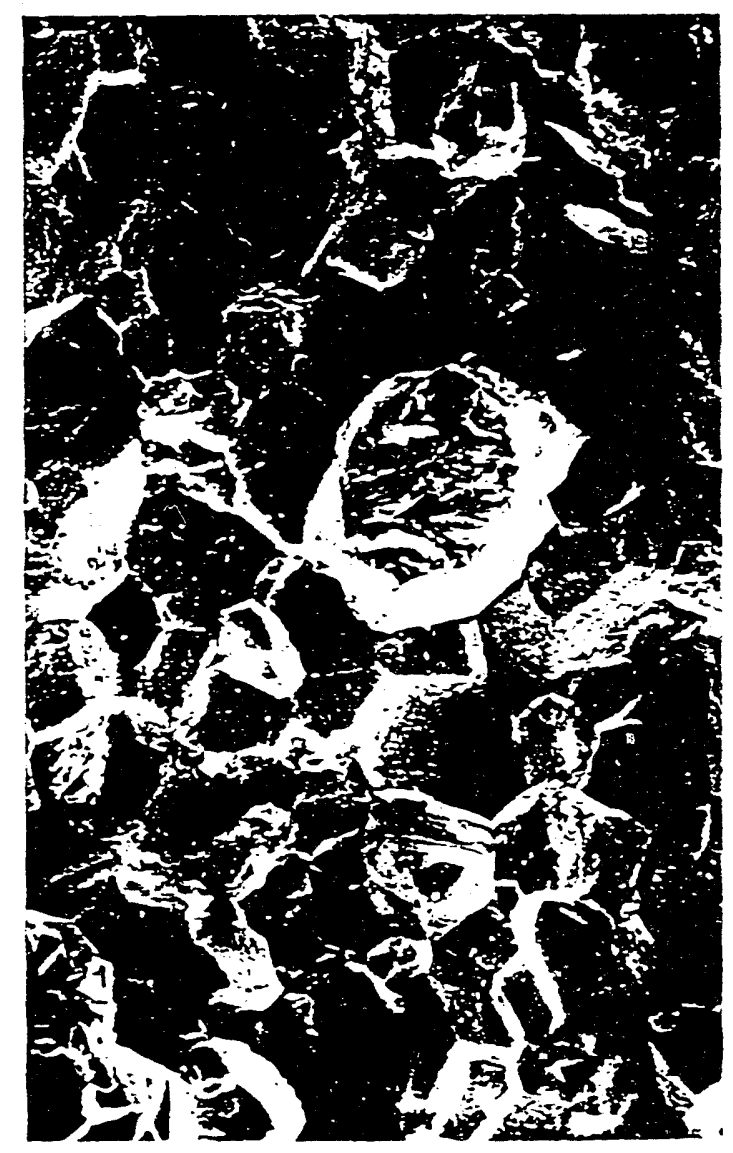



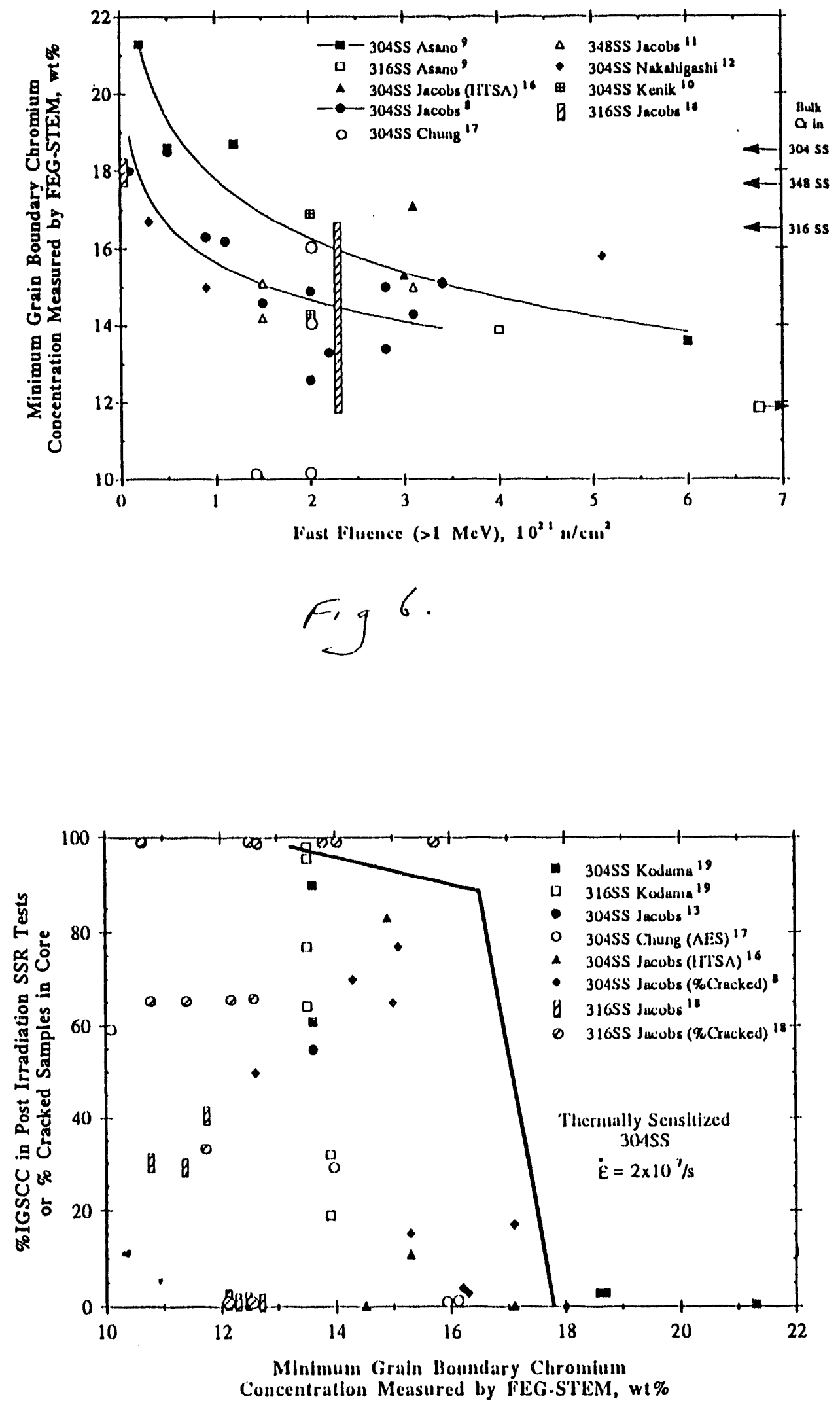

Fig. 7 

